\title{
Tratamento jurídico da obsolescência programada: uma comparação de ações entre o Brasil, EUA e Europa
}

\author{
Legal treatment of planned obsolescence: a comparison \\ of actions among Brazil, USA and Europe
}

\author{
Antonio Edson Oliveira Honorato \\ Universidade Federal Rural do Semi-Árido (UFERSA) \\ Eddla Karina Gomes Pereira \\ Universidade Federal da Paraíba (UFPB)
}

RESUMO A obsolescência programada, tecnicamente compreendida como a decisão do produtor de diminuir o tempo de vida útil de bens de consumo com o fim de maximização dos lucros, passou a ser significativamente discutida a partir da constatação do exaurimento progressivo de matérias-primas, bem como, diante do aumento substancial da produção de lixo. Essa prática vem sendo utilizada há várias décadas por empresas que não assumem um compromisso efetivo com a preservação dos recursos naturais, vinculando as suas decisões tão-somente a partir de critérios lucrativos. Nesse sentido, esta pesquisa tem como objetivo analisar os mecanismos jurídicos existentes com vistas à proteção dos consumidores em razão da obsolescência programada no Brasil, empregando como referencial comparativo experiências do cenário atual dos Estados Unidos e da Europa. Quanto ao aspecto metodológico, trata-se de uma pesquisa exploratória, de caráter qualitativo, com levantamento de dados via pesquisa bibliográfica. Os resultados evidenciam que no Brasil há deficiência na ação das instituições que protegem o consumidor e falta de políticas públicas que atuem na regulação da prática da obsolescência programada, bem como, do ponto de vista legislativo, não há leis vigentes que regulamentem o tema. Verificou-se que existem projetos de leis com tal finalidade, que no momento encontram-se estagnados nos trâmites legais, sem definição sobre o andamento do processo legislativo e consequente aprovação.

Palavras-chave: Obsolescência programada. Tratamento jurídico. Regulação.

\begin{abstract}
Planned obsolescence, technically understood as the producer's decision to reduce the useful life of consumer goods in order to maximize profits, began to be significantly discussed starting from the verification of the progressive depletion of raw materials, as well as of the substantial increase in the production of waste. This practice has been used for several decades by companies that do not make an effective commitment to the
\end{abstract}


preservation of natural resources, binding their decisions only on the basis of lucrative criteria. In this sense, this research has as objective to analyze the existing legal mechanisms with a view to the protection of consumers due to planned obsolescence in Brazil, using as comparative reference the experiences of the current scenario of the United States and Europe. As for the methodological aspect, it is an exploratory research, of qualitative character, with data collection through bibliographic research. The results show that in Brazil there is a deficiency in the action of institutions that protect the consumer and lack of public policies that regulate the practice of planned obsolescence, as well as, from the legislative point of view, there are no laws in force regulating the subject. It has been found that there are draft laws for this purpose, which at the moment are stagnated in the legal proceedings, without definition on the progress of the legislative process and consequent approval.

Keywords: Planned obsolescence. Legal treatMent. Regulation.

\section{INTRODUÇÃo}

A indústria de bens de consumo tem se utilizado de estratégias mais agressivas para incentivar o aumento da venda de produtos. Entre estas, está a prática da obsolescência programada que acontece quando o fabricante de determinado produto, deliberadamente, diminui o ciclo de vida do mesmo, trazendo-o à obsolescência de forma manipulada e prematura. Segundo Keeble (2013), esse é um fenômeno amplamente conhecido, contudo, pouco discutido.

Essa prática induz o usuário do produto ao aumento do consumo, tendo este que comprar um novo bem em espaços de tempo cada vez mais reduzidos, aumentando, assim, a lucratividade das empresas. Para Maycroft (2009), esse processo, em termos gerais, nada mais é do que a criação econômica e cultural do capitalismo, e em termos mais específicos, é o desenvolvimento do desejo pelo consumo nas pessoas.

O consumismo, teoricamente, pode ser entendido como a sensação que causa no indivíduo a falsa necessidade de possuir coisas, fazendo que os desejos inconscientes se transformem em motivos para o consumo (MAYCROFT, 2009). O que acontece, então, é que por meio da obsolescência programada as empresas utilizam as necessidades das pessoas como fato desencadeador do consumismo, a partir do momento em que propositalmente decidem diminuir a vida útil de um produto com a finalidade de aumentar o seu consumo.

Os casos mais evidentes da utilização dessa estratégia são os das empresas de tecnologia, principalmente pelo fato de o avanço tecnológico ser cada vez mais rápido. Mas também porque as empresas desse segmento, geralmente, atuam de forma que seus produtos não tenham reparação em caso de falhas, ou que os mesmos se tornem obsoletos rapidamente. Em muitos casos, quando um dispositivo apresenta falhas, há dificuldade para repor peças defeituosas ou mesmo proceder com um simples reparo em uma assistência técnica independente (SPINKS, 2015). Algumas empresas até previnem seus consumidores para que não realizem tais procedimentos. Ou seja, é uma ação caracterizada pela má-fé do fabricante, no sentido de que pode definir, propositalmente, um curto tempo de vida útil para um produto.

Analisando esse tema do ponto de vista do consumidor, a sensação que se tem é de que os fabricantes de produtos que utilizam a estratégia da obsolescência programada es- 
tão empenhados apenas em incentivar o consumo de seus itens, sem pensar em qualidade de produção, nas necessidades dos consumidores, ou ainda no impacto socioambiental do desenvolvimento da sua atividade econômica. Os mais prejudicados são os cidadãos, considerados individual e coletivamente, que devem contar com uma proteção eficiente que defenda seus direitos contra práticas abusivas da cadeia produtiva.

Nesse contexto, o objetivo deste trabalho é identificar e definir as organizações destinadas à proteção do consumidor, analisando o serviço institucional prestado à sociedade, $\mathrm{e}$ as leis vigentes, sobretudo, quanto à prática da obsolescência programada no Brasil; sendo utilizados como referência comparativa, órgãos atuantes nos Estados Unidos e na Europa. Para isto, serão apresentados os principais órgãos de defesa do consumidor e as ações destes em relação à obsolescência programada, bem como, as leis do Brasil que tratam sobre o tema, trazendo a situação atual dos Estados Unidos e Europa como modelo. Objetivando, assim, a formulação de um panorama do cenário atual a respeito das ações executadas visando à proteção dos consumidores brasileiros contra a estratégia da obsolescência programada.

A importância de estudos dessa natureza é fazer que os consumidores sejam apresentados às ações que estão sendo empregadas para protegê-los da obsolescência programada. Além disso, é oportuno lembrar que o consumidor, sendo a parte mais fraca da relação de consumo, precisa de maior atenção por meio de órgãos de defesa dos seus direitos, bem como, pela legislação dos países que devem regular a atuação de empresas no mercado, evitando perdas substanciais ao consumidor, sobretudo quando tal prejuízo ainda cause repercussões ambientais significativas.

Este estudo é definido como uma pesquisa qualitativa, ancorada em fontes secundárias, as quais foram analisadas por meio de levantamento bibliográfico. Ademais, fez-se uso da pesquisa exploratória com a finalidade de esclarecer conceitos e ideias inerentes ao tema abordado. Por meio do levantamento bibliográfico, apresenta-se o tratamento jurídico da obsolescência programada no Brasil.

O trabalho é composto por mais quatro partes: inicialmente será apresentada a fundamentação teórica, explorando os principais trabalhos sobre a obsolescência programada; em um segundo momento serão abordados os procedimentos metodológicos utilizados para obtenção dos resultados; em seguida, será feita a análise e discussão dos resultados; por fim, exibem-se as considerações finais da pesquisa.

\section{A obsolescênCia Programada}

A obsolescência programada é uma estratégia utilizada pela indústria de bens de consumo para estimular a compra de novos produtos e assim aumentar as vendas do mercado. Segundo Silva (2012), ela serve para encurtar o ciclo de vida dos produtos fabricados, tendo em vista a substituição prematura por novos. Em outras palavras, por meio dessa estratégia os produtos são fabricados para durarem pouco, ou seja, muito menos tempo do que poderiam durar. Isso acontece para que em um futuro breve o consumidor sinta a necessidade de comprar um novo bem, ou adquirir um serviço, que o fabricante oferece em substituição ao antigo (THE ECONOMIST, 2009). 
“A obsolescência programada surgiu no mesmo período em que a produção em massa começou a declinar, porque a demanda dos consumidores não conseguia mais dar vazão ao que era produzido." Assim, a única forma de resolver o problema era construir produtos que não durassem todo o tempo que, de fato, poderiam durar (ALADEOJEBI, 2013, p. 1504, tradução do autor). A obsolescência pode ser encontrada tanto em forma física, quanto em forma técnica.

A obsolescência física é o ato intencional de diminuir a vida útil do bem. Podem ser encontrados vários tipos de obsolescência física, sendo os principais: o desenvolvimento de uma vida funcional limitada, que acontece quando o fabricante deliberadamente define o tempo médio que um produto deve durar; o desenvolvimento para reparos limitados, representado por itens que são muito difíceis de serem consertados e que os altos preços do conserto desencorajam os consumidores a fazê-lo; e o desenho estético, que ocorre quando os produtos são desenvolvidos para parecerem desgastados ou fora de moda rapidamente, para que o consumidor sinta a necessidade de possuir um produto que o desenho estético seja melhor (ALADEOJEBI, 2013).

Já a obsolescência técnica acontece quando o fabricante apresenta ao mercado um novo produto que substitui um já existente (ALADEOJEBI, 2013, p. 1.504, tradução do autor):

É mais comum em produtos eletrônicos. É “voluntário” já que o dispositivo continua funcionando e não necessita ser descartado, mas o estado atual do produto não proporciona mais a satisfação que o consumidor quer ter do seu produto, devido ao fato de que uma nova versão com mais funções está disponível.

Existem ainda várias formas dos produtos se tornarem obsoletos, seja pela função do item, que se torna ultrapassada; pela qualidade, quando o produto é intencionalmente desenvolvido com baixa qualidade para que sua vida útil seja curta; ou ainda pelos desejos do consumidor, que é a obsolescência sensorial criada pela mente do próprio usuário, por acreditar que um produto está ultrapassado porque existem outros mais novos. O Quadro 1 apresenta esses tipos de obsolescência descritos por Packard (1960).

\begin{tabular}{|l|l|}
\hline Obsolescência da função & $\begin{array}{l}\text { Acontece quando um produto se torna ultrapassado a partir } \\
\text { do momento em que um novo produto que apresenta funções } \\
\text { melhores é exibido ao mercado. }\end{array}$ \\
\hline Obsolescência da qualidade & $\begin{array}{l}\text { Essa forma de obsolescência parte de um planejamento e } \\
\text { acontece quando se determina o ciclo de vida do produto, ge- } \\
\text { ralmente, curto. }\end{array}$ \\
\hline Obsolescência de desejabilidade & $\begin{array}{l}\text { Quando mesmo um produto possuindo a qualidade e funções } \\
\text { adequadas, torna-se obsoleto na mente do consumidor, porque } \\
\text { seu estilo ou outra mudança o faz parecer menos desejado. }\end{array}$ \\
\hline
\end{tabular}


Esses tipos de obsolescência são chamados de programados, justamente pelo fato de serem criados pelos próprios fabricantes. São intencionais e partem de uma estratégia de mercado, tendo como objetivo definir o ciclo de vida de um produto, podendo ser considerado má-fé por parte do produtor. Além desses tipos, existe a obsolescência não programada, que é a condição natural em que um bem ou serviço deixa de ser útil, segundo Keeble (2013), é involuntária, não dependendo, pois, da vontade da organização e que pode incapacitar a fabricação ou a comercialização de um produto quando ocorre. A Figura 1 apresenta um resumo dos principais tipos de obsolescência. Sendo as obsolescências de função, qualidade e desejabilidade, consideradas programadas; e a obsolescência natural das coisas não programada.

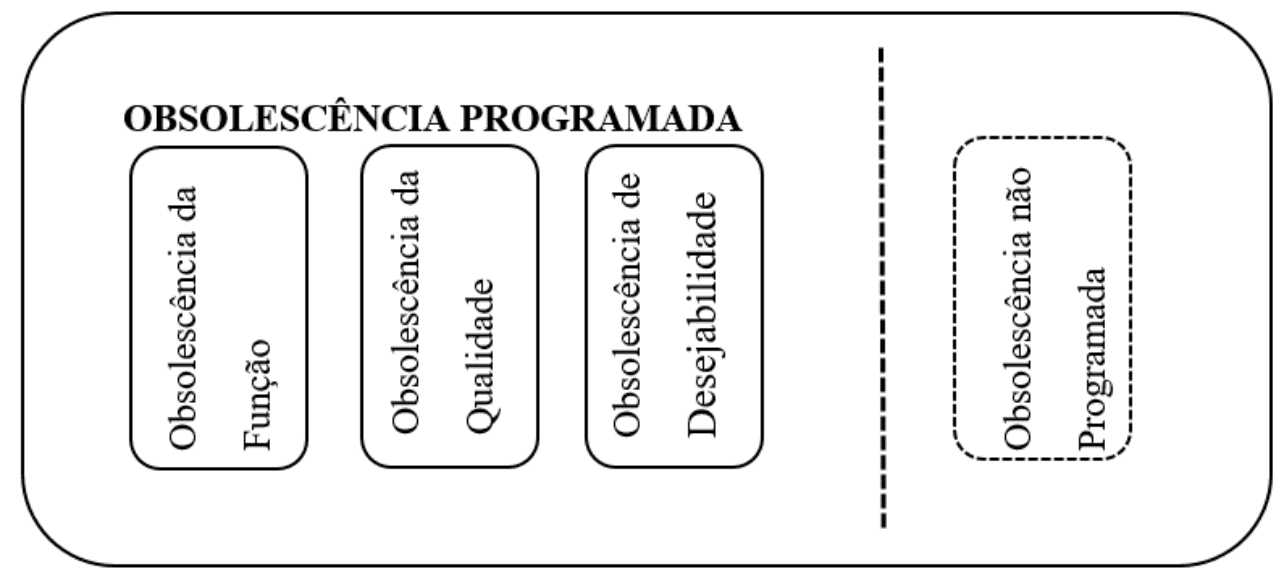

Figura 1 - Tipos de obsolescência.

Fonte: Elaborada pelo autor.

Apesar dos estudos sobre o tema ainda não serem amplamente difundidos, as primeiras pesquisas, a respeito da obsolescência programada, são antigas. No relatório Ending the Depression Through Planned Obsolescence de London (1932), já se havia verificado que apesar de as fábricas estarem prontas para produção em quantidades ilimitadas, a vontade de manter os níveis de produção tinha sido paralisada pela queda no poder de compra dos consumidores. Segundo London (1932), diferente do que aconteceu em tempos passados, as pessoas estavam usando seus carros antigos, seus rádios e roupas velhas muito mais tempo do que as estatísticas estimavam. E, devido a isso, a pesquisa de London sugeria que a obsolescência programada fosse utilizada pelo governo norte-americano como forma de acabar com esta "crise de mercado".

Esse perfil de consumidor não foi aceito pela indústria, que podia e queria fabricar cada vez mais. O contra-ataque veio rápido, de acordo com Packard (1960), pois os fabricantes queriam que o consumo aumentasse e continuasse aumentando. Para isso, apostaram forte nas estratégias de marketing: o objetivo era criar um público com uma vontade tão grande de consumir quanto as máquinas de produzir.

As campanhas publicitárias mostravam que os produtos que as pessoas possuíam estavam defasados e fora de moda, e que se elas desejassem manter seu status perante a sociedade precisavam possuir os novos produtos que lhes eram oferecidos (PACKARD, 
1960). "A publicidade representa um meio de comunicação de massa que pretende criar uma necessidade no consumidor mediante a ilusão e o desejo" (TRABALÓN, 2012, p. 15, tradução do autor).

Contudo, essa estratégia de incentivo ao consumo pode trazer sérios danos não só aos consumidores, mas também ao meio ambiente. A utilização da obsolescência aumenta a produção e o consumo, fazendo que mais produtos sejam fabricados, levando a mais desperdício e muitas vezes ao descarte incorreto dos produtos antigos.

\section{Metodologia}

Em relação à classificação metodológica da pesquisa, trata-se de um estudo exploratório, de natureza bibliográfica, ancorado em fontes secundárias de informação, com análise qualitativa de dados.

O estudo exploratório, segundo Gil (2008), tem a finalidade de desenvolver, esclarecer e modificar conceitos e ideias. Esse tipo de pesquisa objetiva proporcionar maior familiaridade com o tema e, assim, torná-lo mais explícito, e na maioria dos casos assume a forma de pesquisa bibliográfica ou de estudo de caso (GIL, 2002).

Quanto aos procedimentos técnicos, foi utilizada a pesquisa bibliográfica. Esse método, segundo Cervo, Bervian e Silva (2006), procura explicar um problema a partir de um material teórico já publicado em artigos, livros, dissertações e teses. "A principal vantagem da pesquisa bibliográfica reside no fato de permitir ao investigador a cobertura de uma gama de fenômenos muito mais ampla do que aquela que poderia pesquisar diretamente" (GIL, 2008, p. 50).

O levantamento bibliográfico foi realizado entre o período de abril a julho de 2018 , por meio eletrônico nas principais bases de pesquisa de artigos e periódicos nacionais e internacionais, bem como, em livros, relatórios técnicos e websites informacionais, governamentais e institucionais. Foi utilizada a base de dados de periódicos brasileiros SciELO (Scientific Electronic Library Online), o buscador de trabalhos científicos Google Acadêmico e a plataforma SPELL (Scientific Periodicals Electronic Library).

O uso dessas ferramentas de pesquisa proporcionou a utilização de um grande número de artigos e trabalhos científicos que tratam sobre o tema estudado, tendo como finalidade o alcance do objetivo deste trabalho de pesquisa.

Depois de realizar uma breve análise, por meio da pesquisa bibliográfica, dos órgãos de defesa do consumidor e das leis sobre a obsolescência programada no Brasil, foi feita uma pesquisa considerando as iniciativas dos Estados Unidos e Europa a respeito do tema, com o objetivo de utilizar a situação atual como referência. Essas localidades foram escolhidas por serem consideradas polos da economia mundial, bem como, por serem sedes das maiores corporações multinacionais do mundo.

Esta pesquisa se trata, então, de um estudo comparativo e contextualizado acerca da regulamentação da obsolescência programada no Brasil, à luz de iniciativas da Europa e dos Estados Unidos a respeito do tema. De acordo com Fachin (2006, p. 40), o estudo comparativo "Consiste em investigar coisas ou fatos e explicá-los segundo suas semelhanças e 
suas diferenças". Utilizou-se como enfoque a obsolescência programada do ponto de vista do consumidor. Levando em consideração o entendimento político e jurídico do direito do consumidor sobre o assunto, avaliando as consequências trazidas e os meios de regulação dessa prática no Brasil.

\section{ANÁLISE E DISCUSSÃo dOS RESULTADOS}

A obsolescência programada é uma estratégia unilateral, que objetiva formar no consumidor a ideia de que é necessário que ele substitua um bem que já possui, não deixando oportunidade para que decida se precisa ou não de um novo bem. De um lado, estão as necessidades das organizações, que veem na estratégia de obsolescência programada a oportunidade para o aumento de vendas e uma forma de se evitar que a demanda diminua. De outro lado, estão os consumidores, que movem a economia, na busca de uma melhor qualidade dos bens e serviços.

Nesse dilema, o elo mais fraco é o consumidor, já que a decisão por utilizar a estratégia de obsolescência é do fabricante. Deve, portanto, haver um ente regulador que limite a atuação das empresas, definindo até que ponto a utilização de uma estratégia de mercado pode ser adotada sem causar danos ao cliente.

Nesse sentido, a presente pesquisa abordará quais são os órgãos responsáveis pela defesa dos consumidores no Brasil, utilizando como referência comparativa o cenário presente dos Estados Unidos e Europa, e como eles atuam para regular um mercado com estratégias econômicas cada vez mais agressivas. Além disso, neste tópico será apresentado o panorama da legislação atual relacionada à obsolescência programada nessas três regiões do mundo.

\section{1 Órgãos responsáveis pela defesa dos consumidores no Brasil}

No Brasil, o Programa de Orientação e Proteção ao Consumidor (Procon) e a Delegacia do Consumidor (Decon) são os principais órgãos de defesa do consumidor e estão presentes nas 27 unidades federativas brasileiras. Além destes, existe também o Departamento de Proteção e Defesa do Consumidor (DPDC) (PORTAL DO BRASIL, 2009). Esses órgãos públicos atuam tendo como referência o Código de Defesa do Consumidor (CDC).

Auxiliando as unidades físicas desses órgãos, há o website governamental "Consumidor.gov", que facilita a comunicação entre o fornecedor e seus consumidores pela internet. Essa ferramenta age como um conciliador, em que o usuário de um produto ou serviço, que busca solucionar problemas com empresas, abre um chamado na própria plataforma e a empresa reclamada se compromete a receber, analisar e responder as reclamações em um prazo de até dez dias. A iniciativa de criação dessa ferramenta foi do Ministério da Justiça e é monitorada pela Secretaria Nacional do Consumidor e pelos Procons estaduais.

Com essas mesmas características, existe o website "Reclame Aqui", criado pela iniciativa privada. Essa ferramenta é mais conhecida pelos consumidores e tem o mesmo objetivo do website "Consumidor.gov", ou seja, oportunizar a comunicação entre consumidor e fabricante ou fornecedor de produtos ou serviços, de forma a possibilitar a conciliação de conflitos e/ou publicizar seus atos, sejam eles positivos ou negativos. As reclamações são enviadas di- 
retamente para as empresas cadastradas, que buscam sanar os problemas dos usuários quanto ao atendimento, compra e venda de produtos e serviços, sob pena de, em não resolvendo as reclamações, ter a sua reputação classificada como negativa no próprio site.

Já nos Estados Unidos, as principais organizações de proteção ao consumidor são: Consumers Union (CU), Consumer Federation of America (CFA) e a National Consumers League (NCL). Sendo a Consumers Union considerada o maior órgão independente de educação para o consumidor e de realização de testes em produtos do mundo (GUGLINSKI, 2013; REIBOLDT; MALLERS, 2014).

Além desses, os norte-americanos contam com o Better Business Bureau (BBB), um serviço de defesa do consumidor on-line. O BBB foi fundado em 1912 e é uma organização sem fins lucrativos focada na promoção da confiabilidade do mercado para o consumidor e conta com organizações locais incorporadas nos Estados Unidos e Canadá. Esse órgão ajuda os consumidores a encontrarem marcas e empresas em que possam confiar. Segundo dados da própria entidade, em 2016 as pessoas recorreram ao BBB mais de 167 milhões de vezes para buscar perfis de empresas, sendo esse um dos websites mais visitados dos Estados Unidos (BBB, 2018).

Enquanto na Europa, a European Association for the Coordination of Consumer Representation in Standardisation (ANEC), a The European Consumer Organisation (BEUC) e a European Consumers Union (ECU) são os principais órgãos atuantes nas questões pró-consumidores da União Europeia.

Além dessas organizações, existe também a The European Consumer Center Network (ECC-Net). Trata-se de uma rede composta por 30 escritórios presentes nos 28 Estados membros da União Europeia, Noruega e Islândia. O objetivo da rede é oferecer serviço de ajuda e aconselhamento gratuito para consumidores, sendo o serviço prestado de forma on-line ou em um dos 30 escritórios espalhados pela Europa. Por meio dela o consumidor consegue assistência para conhecer seus direitos e aconselhamento para entender como deve agir com problemas decorrentes da relação de consumo com empresas (EUROPEAN COMMISSION, 2018).

\subsection{Breves considerações sobre o panorama da legislação atual do Brasil em relação à obsolescência programada}

No Brasil, não há uma lei específica sobre a obsolescência programada. O Código de Defesa do Consumidor (CDC), principal instrumento de proteção ao consumidor, limitouse, no parágrafo único do artigo 32, a determinar a oferta de componentes e peças de reposição enquanto não cessar a fabricação ou importação do produto. E, quando cessada a fabricação, a oferta de tais peças deve ainda perdurar por um razoável período, prazo que deverá ser compatível com o tempo de vida útil médio do produto.

Em relação à jurisprudência dos órgãos do judiciário brasileiro, há poucos precedentes relacionados à obsolescência programada. O motivo é que, segundo Rodas (2015), é muito difícil comprovar a prática dessa estratégia, além de não haver muita literatura sobre o tema. Ademais, para a condenação de um fabricante pela má-fé decorrente da diminuição proposital do tempo de vida útil de certo produto ou serviço, são necessárias provas periciais e demais meios objetivos de produção de provas. 
Em uma das únicas decisões tomadas pelo Superior Tribunal de Justiça (STJ), o comprador obteve de um fabricante de tratores reparos mecânicos, mesmo já tendo sido cessada a garantia do bem. No processo, o consumidor afirmava que o desgaste do veículo adquirido não fora natural e sim em virtude de um defeito proposital do projeto, tratando-se, então, de um vício oculto. A obsolescência programada foi citada como sendo uma medida para reduzir artificialmente a durabilidade do produto ou o ciclo de vida de seus componentes, para que fosse forçada uma nova compra de um mesmo produto (BRASIL, STJ, 2012). Neste caso, o judiciário julgou procedente a demanda em favor do consumidor.

Atualmente, o que se tem no Brasil a respeito da obsolescência programada é um projeto de lei de iniciativa de um ministro do STJ, o qual foi entregue à comissão de reforma do CDC, bem como, um projeto de lei de iniciativa do legislativo (PL 5367/2013) que se encontra arquivado.

A proposta do STJ sugere que, sem limitar o avanço tecnológico, o CDC obrigue os fabricantes a indicarem nos seus produtos a vida útil deles e preveja punição para as empresas que praticarem a obsolescência programada (RODAS, 2015). Enquanto o Projeto de Lei 5.367 obriga que o fabricante de um produto disponibilize ao consumidor informações sobre seu tempo de vida útil, ressaltando que produtos fabricados com curta durabilidade geram dois efeitos: falta de poder de escolha pelo consumidor, baseando-se apenas no preço; e o impacto ambiental com o aumento do lixo inorgânico (CÂMARA DOS DEPUTADOS, 2014). O Quadro 2 apresenta as principais características das duas propostas.

\begin{tabular}{|c|c|}
\hline Proposta Ministro STJ & Projeto de Lei 5.367/2013 \\
\hline $\begin{array}{l}\text { - Considera que a obsolescência programada deve ser vista pelo } \\
\text { CDC como uma prática abusiva; } \\
\text { - A responsabilidade do fornecedor de bens duráveis deve observar o } \\
\text { tempo de vida útil do bem e não a garantia contratual; } \\
\text { - Indicação do tempo de vida útil ou o número de utilizações previs- } \\
\text { ta, no próprio produto; } \\
\text { - Obrigação dos fornecedores de produtos maléficos ao meio am- } \\
\text { biente a coletarem produtos obsoletos; } \\
\text { - Aplicação de multas para empresas que praticarem a obsolescência } \\
\text { programada; } \\
\text { - Certificação por órgão oficial de empresas comprometidas a com- } \\
\text { bater a obsolescência programada; } \\
\text { - Em contratos públicos, dar-se preferência às empresas com certifi- } \\
\text { cação antiobsolescência; } \\
\text { - Informação clara ao consumidor sobre o impacto da atualização } \\
\text { de programas e softwares quanto ao desempenho dos equipamentos. }\end{array}$ & $\begin{array}{l}\text { Esse projeto destaca que muitos fornecedores, } \\
\text { principalmente de eletrodomésticos e eletroele- } \\
\text { trônicos, reduzem a vida útil de produtos proposi- } \\
\text { talmente e dificultam a reparação dos defeituosos } \\
\text { para que sejam usados pelo menor tempo possível. } \\
\text { Com a informação sobre o tempo de vida útil, o } \\
\text { consumidor teria a possibilidade de decidir a com- } \\
\text { pra de um produto, avaliando sua durabilidade. } \\
\text { Pela proposta, a punição das empresas que não } \\
\text { cumprissem o disposto na nova lei iria de multas } \\
\text { até interdição das atividades do estabelecimento. }\end{array}$ \\
\hline
\end{tabular}

Quadro 2 - Legislação atual sobre obsolescência programada no Brasil. Fonte: Adaptado de Brasil (STJ, 2012) e Câmara dos Deputados (2014). 
Dessa forma, no âmbito jurídico, percebe-se que o principal instrumento de proteção ao consumidor no Brasil não trata especificamente da obsolescência programada. Enquanto as duas propostas para criação de leis específicas na regulação dessa prática encontram-se com conduções legislativas paralisadas. Isso interfere então, na atuação dos órgãos de defesa do consumidor, tendo em vista que levam em consideração a legislação vigente no país para a aplicação de penalidades.

\subsection{Como agem os órgãos de defesa do consumidor em relação à obsoles- cência programada no Brasil?}

No Brasil, uma das maiores preocupações do Procon em relação à obsolescência programada é com o aumento da produção do lixo eletrônico, devido à diminuição do tempo de vida útil do produto e seu descarte incorreto. O órgão entende como necessária a organização de uma frente da sociedade civil para mudar os padrões de produção e consumo, e com isso diminuir o descarte irregular e desnecessário de toneladas de lixo eletrônico e tóxico no planeta. O Procon defende o fim da obsolescência programada, ressaltando que as organizações precisam garantir o acesso transparente à informação quanto à fabricação de produtos e garantir ao consumidor a produção de bens com qualidade e durabilidade, assumindo a responsabilidade pelo ciclo de vida dos seus produtos (PROCONRJ, 2012).

Outro motivo que leva ao aumento de consumo e, por conseguinte, ao aumento da geração de lixo tecnológico, é a falta de disponibilidade de assistência técnica especializada. Uma pesquisa realizada pelo DPDC verificou a quantidade de assistências técnicas dos cinco maiores fabricantes de celulares em todo país. Os resultados da pesquisa mostraram que o número de assistências técnicas é ínfimo, sendo que em vários Estados alguns dos fabricantes não possuíam qualquer posto especializado. Esse problema gera para o consumidor a dificuldade de submeter seu aparelho eletrônico a um simples conserto, fazendo que desista de realizá-lo e preferir comprar um novo produto. Além disso, a demora para devolver o produto, falta de peças de reposição e de garantia também fazem o consumidor optar por não contratar o serviço (IDEC, 2014).

Os serviços on-line de proteção ao consumidor "Reclame Aqui" e "Consumidor.gov" estão repletos de reclamações de clientes que atribuem as falhas dos seus produtos à obsolescência programada. Em muitas das reclamações os consumidores apontam o curto tempo de vida dos aparelhos e a demora para entrega de produtos enviados para conserto.

Em uma análise geral, dos três principais órgãos de proteção ao consumidor no Brasil (Procon, Decon e DPDC), nenhum apresenta projetos ou campanhas contra a obsolescência programada. Esses órgãos atuam, geralmente, apenas como conciliadores, levando em consideração a legislação vigente e prestando auxílio ao consumidor em relações de consumo que desrespeitam seus direitos. O Quadro 3 apresenta um resumo da ação desses órgãos. 


\begin{tabular}{|c|c|}
\hline \multicolumn{2}{|c|}{ Programa de Orientação e Proteção ao Consumidor (Procon) } \\
\hline Como age & Posição sobre a obsolescência programada \\
\hline $\begin{array}{l}\text { Age como orientador e conciliador do consumidor. Busca solucionar } \\
\text { conflitos entre empresa e cliente, levando em consideração a legisla- } \\
\text { ção vigente, caso não haja conciliação entre as partes o órgão orienta } \\
\text { o consumidor a entrar com processo contra a reclamada, em juizados } \\
\text { especiais ou justiça comum. }\end{array}$ & $\begin{array}{l}\text { Avalia a obsolescência como prejuízo para o consu- } \\
\text { midor, bem como, para o meio ambiente. Mas não } \\
\text { apresenta qualquer projeto ou campanha contra a } \\
\text { utilização dessa estratégia pelas organizações. }\end{array}$ \\
\hline \multicolumn{2}{|c|}{ Delegacia do Consumidor (Decon) } \\
\hline Como age & Posição sobre a obsolescência programada \\
\hline $\begin{array}{l}\text { Esse órgão recebe denúncias de crimes contra as relações de consu- } \\
\text { mo, e instaura inquéritos policiais para apurar os fatos. Concluído o } \\
\text { inquérito, a Decon o envia ao Ministério Público, que decide pela } \\
\text { representação ou não da denúncia. }\end{array}$ & $\begin{array}{l}\text { Não tem posição sobre a obsolescência programa- } \\
\text { da. Atua apenas com apuração de denúncias de cri- } \\
\text { mes previstos em lei. }\end{array}$ \\
\hline \multicolumn{2}{|c|}{ Departamento de Proteção e Defesa do Consumidor (DPDC) } \\
\hline Como age & Posição sobre a obsolescência programada \\
\hline $\begin{array}{l}\text { O DPDC atua de forma a coordenar a política e ações do Sistema Na- } \\
\text { cional de Defesa do Consumidor (SNDC), sendo essa sua principal } \\
\text { atribuição. Também age concretamente em casos de relevância na- } \\
\text { cional e nos assuntos de maior interesse para a classe consumidora. }\end{array}$ & $\begin{array}{l}\text { Apesar de desenvolver ações voltadas ao aper- } \\
\text { feiçoamento do sistema, à educação para o con- } \\
\text { sumo e para melhor informação e orientação dos } \\
\text { consumidores, não apresenta qualquer projeto que } \\
\text { regule a obsolescência programada no país. }\end{array}$ \\
\hline
\end{tabular}

\section{Quadro 3 - Como agem os órgãos de defesa do consumidor no Brasil.}

Fonte: Adaptado de Portal do Brasil (2009).

Quanto aos mecanismos on-line (Reclame Aqui e Consumidor.gov), a atuação é apenas como uma ferramenta de conexão entre consumidor e empresa. O website recebe a reclamação do cliente e envia à empresa. Neste caso, ambos tentam um acordo, sem qualquer inervação da entidade. Caso não haja acordo, o consumidor deve procurar órgãos de defesa do consumidor, os juizados especiais ou a justiça comum, dependendo do valor da ação.

\subsection{Breves considerações sobre o cenário jurídico atual dos Estados Uni- dos e da Europa em relação à obsolescência programada}

Nos Estados Unidos não há, atualmente, leis nacionais que proíbam a utilização da obsolescência programada pelas empresas. No entanto, há casos específicos nos quais o Estado interveio para regular o tempo de vida útil de produtos ou a forma de fabricação de determinados itens, como aconteceu em 2012, quando o governo norte-americano baniu a produção de berços com grades laterais ajustáveis em altura (HG.ORG, 2018).

O governo tomou tal decisão devido a duas mortes de crianças ocorridas naquele ano, e de pelo menos trinta mortes na última década e de vários recalls - convocação por parte do fabricante para correção e reparos de defeitos ou substituição de produtos. As empresas, nesse caso, passaram a ser obrigadas a fabricar berços apenas com barras laterais fixas. Apesar de não ser um caso de obsolescência programada, essa medida mostra que o governo norte-americano tem atuado na regulação de determinados produtos com vistas à proteção do consumidor. 
Já na Europa, o país mais avançado em relação a leis que tratam da obsolescência programada é a França. Um decreto do governo francês determina que os fabricantes devem informar aos consumidores o tempo de vida útil dos seus produtos. As empresas francesas também têm que informar quanto tempo peças do produto estarão disponíveis no mercado (KHALEELI, 2015). A obsolescência programada se tornou crime na França, no ano de 2015. Com a aprovação dessa lei, o governo francês objetiva proteger os consumidores contra a estratégia da obsolescência, enquanto reduz o desperdício, o volume de lixo inorgânico e promove a preservação dos recursos naturais (SUEZ, 2015).

A legislação europeia também estabelece dois anos de garantia legal para qualquer produto. Se o produto apresentar qualquer falha ou não funcionar da maneira que foi anunciado, o vendedor deve consertar ou substituir o produto, livre de qualquer taxa, ou oferecer uma redução no preço pago ou reembolso do valor total. No Brasil, também ocorre o mesmo, mas com uma diferença significativa no tempo de garantia legal, sendo este de noventa dias. Na Europa, o comerciante deverá sempre oferecer uma solução para os defeitos ou falhas do produto durante a garantia de dois anos, e em alguns países o consumidor também pode solicitar soluções diretamente ao fabricante do item (YOUR EUROPE, 2018).

\subsection{Como agem os órgãos de defesa do consumidor em relação à obsoles- cência programada nos Estados Unidos e na Europa?}

Nos Estados Unidos, os principais órgãos de defesa do consumidor não apresentam ações específicas que pautem a utilização da estratégia de obsolescência programada pelas empresas e as consequências por ela trazidas para os consumidores. Existem, porém, o que os pesquisadores do direito chamam de "leis alternativas". Exemplo disso, é a obrigação imposta pelo governo norte-americano para as montadoras de veículos, que devem garantir que os cintos de segurança utilizados nos seus automóveis durem por um período mínimo de cinco anos ou oitenta mil quilômetros (HG.ORG, 2018). O Quadro 4 apresenta as principais ações dos órgãos de defesa do consumidor dos Estados Unidos.

$\mathrm{Na}$ Europa, dos principais órgãos de defesa do consumidor analisados, apenas a $E u$ ropean Association for the Coordination of Consumer Representation in Standardisation (ANEC) - organização sem fins lucrativos financiada majoritariamente pela União Europeia - e a The European Consumer Organisation (BEUC) - organização não-governamental financiada pela União Europeia, membros da organização e outros projetos específicos se posicionam sobre a obsolescência programada. Um estudo organizado por uma empresa europeia de pesquisas verificou que $92 \%$ dos participantes concordaram que as empresas deveriam indicar nas embalagens dos produtos o seu tempo de vida útil (EUROBAROMETER, 2013). Isso faria que o fabricante se comprometesse a produzir bens com mais durabilidade, e daria oportunidade para o consumidor fazer uma análise mais profunda sobre o custo-benefício do produto. A obsolescência programada na Europa é vista como uma obsolescência negligente e que deve ser evitada (EPRS, 2016).

A Swiss Consumer Organisation (SKS), uma das 43 organizações de defesa do consumidor membras da BEUC, em 2013, recebeu mais de 400 reclamações de clientes relacionadas ao curto tempo de vida útil de produtos, sendo a maioria delas devido às falhas em aparelhos eletrônicos, como computadores, celulares e eletrodomésticos (BEUC, 2014). O Quadro 5 mostra como agem os principais órgãos da Europa em relação à obsolescência programada. 


\begin{tabular}{|c|c|}
\hline \multicolumn{2}{|c|}{ Consumers Union (CU) } \\
\hline Como age & Posição sobre a obsolescência programada \\
\hline $\begin{array}{l}\text { Esse órgão busca ajudar os consumidores a tomar me- } \\
\text { lhores decisões mercadológicas e a reforçar a necessi- } \\
\text { dade de o mercado considerar sempre as necessidades } \\
\text { do consumidor primeiro. Foi criada em } 1936 \text { e é consi- } \\
\text { derada a maior organização de defesa do consumidor do } \\
\text { mundo (REIBOLDT; MALLERS, 2014), a Consumers } \\
\text { Union faz parte da Consumers Reports que tem como } \\
\text { principais atribuições publicar revistas e material didáti- } \\
\text { co com orientações para os consumidores do país. }\end{array}$ & $\begin{array}{l}\text { Atua como orientador do consumidor, não apresenta posição } \\
\text { quanto à legalidade ou não da utilização da obsolescência pro- } \\
\text { gramada pelas organizações. }\end{array}$ \\
\hline \multicolumn{2}{|c|}{ Consumer Federation of America (CFA) } \\
\hline Como age & Posição sobre a obsolescência programada \\
\hline $\begin{array}{l}\text { Promove os interesses do consumidor por meio de pes- } \\
\text { quisas, educação e defesa de direitos. Como organização } \\
\text { de defesa do consumidor, atua em prol de políticas pró- } \\
\text {-consumidor em contato direto com legisladores do país. }\end{array}$ & $\begin{array}{l}\text { Atua como investigador de questões importantes para os con- } \\
\text { sumidores, por meio de pesquisas. Dissemina as informações } \\
\text { relacionadas ao consumidor para o público em geral e para no- } \\
\text { ticiários, bem como para legisladores e outros públicos interes- } \\
\text { sados. Não apresenta ainda um posicionamento sobre o risco } \\
\text { da obsolescência programada para o consumidor. }\end{array}$ \\
\hline \multicolumn{2}{|c|}{ National Consumers League (NCL) } \\
\hline Como age & Posição sobre a obsolescência programada \\
\hline $\begin{array}{l}\text { Representa os consumidores em prol da defesa de direi- } \\
\text { tos perante o mercado e em questões trabalhistas. Essa } \\
\text { entidade tem como objetivo promover um mercado justo } \\
\text { para trabalhadores e consumidores. A NCL defende que } \\
\text { os produtos devem ser produzidos e distribuídos a um } \\
\text { preço razoável e em quantidade adequada, sempre sob } \\
\text { condições de trabalho justas, seguras e saudáveis. }\end{array}$ & $\begin{array}{l}\text { Por meio de petições e pesquisas representa os consumidores } \\
\text { e defende seus direitos. Em muitos casos trabalha para mudar } \\
\text { a legislação trabalhista e de proteção ao consumidor por meio } \\
\text { de campanhas. Até o momento não apresentou um projeto ou } \\
\text { campanha específica para obsolescência programada. }\end{array}$ \\
\hline
\end{tabular}

Quadro 4 - Como agem os órgãos de defesa do consumidor dos Estados Unidos. Fonte: Adaptado de Consumers Union (2018), CFA (2018) e NCL (2018).

Dos três principias órgãos de defesa do consumidor na Europa, a BEUC é o mais representativo em relação à obsolescência programada, tendo em vista que essa entidade tem uma posição contrária à utilização dessa estratégia pelas empresas, e mantém campanhas que promovem o respeito aos direitos dos consumidores, além de apresentar soluções que precisam ser tomadas para erradicar a obsolescência programada no continente europeu.

\subsection{Análise da situação regulamentar atual da obsolescência programa- da no Brasil em relação aos Estados Unidos e Europa}

Com relação ao âmbito jurídico, no Brasil existem dois projetos de lei, um proposto pelo Superior Tribunal de Justiça e o outro pelo poder legislativo brasileiro. Ambos os projetos se encontram com andamentos paralisados e com prosseguimentos incertos. Nos Estados Unidos, não foram encontradas leis ou projetos de lei que pautem ou regulem a prática da obsolescência programada. Já na Europa, estão concentrados os maiores avanços regulamentares acerca da utilização da obsolescência programada pelas organizações. $\mathrm{Na}$ 
França, por exemplo, essa prática é crime previsto em lei desde 2015. Nesse país, as empresas são obrigadas a informar aos consumidores o tempo de vida útil de cada produto. $\mathrm{O}$ tempo de garantia legal de dois anos, previsto na legislação europeia, também é um ganho significativo para o consumidor.

\begin{tabular}{|c|c|}
\hline \multicolumn{2}{|c|}{ European Association for the Coordination of Consumer Representation in Standardisation (ANEC) } \\
\hline Como age & Posição sobre a obsolescência programada \\
\hline $\begin{array}{l}\text { Atua representando os interesses dos consumidores } \\
\text { europeus na criação de técnicas de padronização, es- } \\
\text { pecialmente as que são desenvolvidas para dar apoio à } \\
\text { implementação das leis e políticas públicas da Europa. } \\
\text { Essa organização também opera de forma a influenciar } \\
\text { a criação ou revisão da legislação europeia relacionada } \\
\text { a produtos e serviços que possam afetar o consumidor, } \\
\text { especialmente no que depende da padronização. }\end{array}$ & $\begin{array}{l}\text { A principal atribuição da ANEC está relacionada à padroniza- } \\
\text { ção de produtos e serviços, esse órgão entende a obsolescên- } \\
\text { cia programada como um assunto que tem significativamente } \\
\text { atraído a atenção do público e que isso seria uma boa justifica- } \\
\text { tiva para fazê-lo ser prioridade (ANEC, 2015). A maior preocu- } \\
\text { pação da ANEC, em relação ao tema, é quanto aos malefícios } \\
\text { que a obsolescência programada pode trazer para o meio am- } \\
\text { biente (ANEC, 2013). }\end{array}$ \\
\hline \multicolumn{2}{|c|}{ The European Consumer Organisation (BEUC) } \\
\hline Com & Posição sobre a obsolescência programada \\
\hline $\begin{array}{l}\text { A BEUC é o maior órgão pró-consumidor da Europa, } \\
\text { fundada em 1962, reúne } 43 \text { organizações de defesa do } \\
\text { consumidor de } 31 \text { países da Europa. A BEUC representa } \\
\text { seus membros e defende os interesses dos consumidores } \\
\text { observando as decisões constitucionais da União Euro- } \\
\text { peia, atuando como a "voz do consumidor europeu". }\end{array}$ & $\begin{array}{l}\text { A BEUC vê a obsolescência programada como uma conse- } \\
\text { quência negativa para o consumidor e, por isso, desde } 2014 \\
\text { mantém a campanha "Produtos Duráveis". Essa campanha de- } \\
\text { fende produtos mais sustentáveis e maior respeito aos direitos } \\
\text { do consumidor. A BEUC oferece um website específico em } \\
\text { que o consumidor pode entender melhor seus direitos e encon- } \\
\text { trar recomendações sobre como agir em compras de produtos } \\
\text { defeituosos (CONSUMER CHAMPION, 2014). Como prin- } \\
\text { cipais problemas trazidos pela prática da obsolescência progra- } \\
\text { mada, a BEUC cita os problemas com o meio ambiente, com as } \\
\text { questões sociais, saúde pública, culturais e econômicas. Como } \\
\text { soluções, defende conter casos em flagrante, melhorar o setor } \\
\text { de reparos e suporte das empresas, padronização de produtos e } \\
\text { serviços, definir a expectativa de vida útil de produtos, estender } \\
\text { a garantia, aumentar a conscientização do consumidor e apoiar } \\
\text { estudos sobre o tema (BEUC, 2014). }\end{array}$ \\
\hline \multicolumn{2}{|c|}{ European Consumers Union (ECU) } \\
\hline Como age & Posição sobre a obsolesc \\
\hline $\begin{array}{l}\text { Tem como objetivo representar os consumidores na co- } \\
\text { munidade europeia, trabalhar pela defesa de seus direitos } \\
\text { e participar ativamente das políticas que tratam do con- } \\
\text { sumidor, adequando e corrigindo informações, prestan- } \\
\text { do assistência aos cidadãos europeus e representando o } \\
\text { consumidor nos processos legislativos. }\end{array}$ & $\begin{array}{l}\text { Defende e difunde os direitos do consumidor. Busca conci- } \\
\text { liar os interesses da administração pública e empresas, oferece } \\
\text { consultoria jurídica e informa sobre temas relacionados ao con- } \\
\text { sumo. Não apresenta uma posição específica sobre a obsoles- } \\
\text { cência programada. }\end{array}$ \\
\hline
\end{tabular}

\section{Quadro 5 - Como agem os órgãos de defesa do consumidor da Europa.}

Fonte: Adaptado de ANEC (2018), BEUC (2018) e ECU (2018).

Levando em consideração a posição dos principias órgãos de defesa do consumidor no Brasil, apenas o Procon apresenta posição sobre a obsolescência programada. Nos Estados Unidos, nenhum dos órgãos pesquisados mostrou posição específica a respeito do uso 
dessa prática pelas empresas. Enquanto na Europa, a ANEC e a BEUC mostram posições contrárias à utilização.

O Quadro 6 apresenta a análise da regulamentação do ponto de vista jurídico e a posição dos órgãos de proteção ao consumidor do Brasil, Estados Unidos e da Europa em relação à obsolescência programada.

\begin{tabular}{|c|c|}
\hline \multicolumn{2}{|c|}{ Brasil } \\
\hline Regulamentação jurídica & Órgãos de proteção ao consumidor \\
\hline $\begin{array}{l}\text { Não há leis específicas sobre a prática da obsolescência pro- } \\
\text { gramada em vigor atualmente. Existem projetos de lei que } \\
\text { no momento estão estagnados nos trâmites legais. }\end{array}$ & $\begin{array}{l}\text { Apenas o Procon mostrou posição sobre a obsolescência } \\
\text { programada, contudo não possui campanhas a respeito do } \\
\text { tema. A Decon e o DPDC até o momento não apresentam } \\
\text { posições específicas acerca do assunto. }\end{array}$ \\
\hline \multicolumn{2}{|c|}{ Estados Unidos } \\
\hline Regulamentação jurídica & Órgãos de proteção ao consumidor \\
\hline $\begin{array}{l}\text { Não há leis vigentes que regulem a prática da obsolescência } \\
\text { no país, contudo, em alguns casos específicos, o próprio Es- } \\
\text { tado tem regulado o tempo de vida útil de produtos. }\end{array}$ & $\begin{array}{l}\text { Nenhum dos órgãos pesquisados apresentou posição sobre } \\
\text { a utilização da obsolescência programada pelas empresas. }\end{array}$ \\
\hline \multicolumn{2}{|c|}{ Europa } \\
\hline Regulamentação jurídica & Órgãos de proteção ao consumidor \\
\hline $\begin{array}{l}\text { Na Europa, o tempo de garantia legal é de dois anos, re- } \\
\text { gulando então o tempo de vida útil do produto. Na Fran- } \\
\text { ça, a prática da obsolescência é considerada crime desde } \\
2015 \text {, e as empresas devem indicar o tempo de vida útil dos } \\
\text { produtos fabricados. }\end{array}$ & $\begin{array}{l}\text { A ANEC e a BEUC, organizações não governamentais, têm } \\
\text { sido os órgãos mais atuantes em relação à obsolescência } \\
\text { programada. A BEUC mantém desde } 2014 \text { uma campanha } \\
\text { contra essa prática. }\end{array}$ \\
\hline
\end{tabular}

\section{Quadro 6 - Regulamentação jurídica e posição dos órgãos de proteção ao consumidor quanto à obsolescência programada no Brasil, Estados Unidos e Europa.} Fonte: Dados da pesquisa.

Assim, verifica-se que apesar de, no Brasil, o Procon ter uma posição contrária à obsolescência programada, não desenvolve uma campanha de orientação e proteção ao consumidor contra essa prática. Isso pode ser devido ao fato de que, do ponto de vista jurídico, não há leis específicas de regulação, e os projetos de leis que tratam o tema estão paralisados. Esses órgãos levam em consideração a legislação vigente no país, e em razão da falta de leis específicas podem encontrar barreiras para atuarem na regulação do mercado.

Nos Estados Unidos, as principais organizações pró-consumidor não têm posição específica sobre o assunto, bem como não foram encontradas leis que regulem a utilização dessa prática pelas empresas. Na Europa, verificou-se os maiores avanços tanto institucional quanto jurídico em relação à regulação da obsolescência programada. Existem leis específicas que tornam o uso dessa prática crime, e os principais órgãos de proteção ao consumidor mantêm campanhas antiobsolescência no continente. 


\section{CONSIDERAÇões FINAIS}

Com o objetivo de aumentar as vendas e, por conseguinte, sua lucratividade, as empresas empregam diversos tipos de recursos, um deles é a obsolescência programada. Essa estratégia consiste em definir um curto tempo de vida útil de produtos e serviços, de forma que eles não durem muito, podendo então ser compreendida como má-fé do produtor. Ela pode ser analisada de diferentes pontos de vista, como da economia ou do meio ambiente. Esta pesquisa focou a visão do consumidor e nas consequências que a utilização da obsolescência programada pode lhe trazer.

A obsolescência programada pode ser aplicada de diversas formas, mas todas elas têm a mesma finalidade, aumentar o consumo. O que se discutiu neste trabalho, no entanto, foi a questão da legalidade da rede de proteção que os consumidores têm, a fim de evitar abusos por parte dos fabricantes no Brasil. As empresas estão sempre buscando novas formas de aumentarem seus números, vendas e receitas, mas o que deve ser debatido é até que ponto uma estratégia pode ser usada para obter tal finalidade.

Por meio desta pesquisa, verificou-se que o consumidor, elo mais fraco na relação de consumo, pode sofrer grandes perdas devido à obsolescência programada. Quando uma organização decide tornar um produto ou serviço obsoleto propositalmente, ela faz isso por conta própria, tendo em vista apenas suas necessidades, ou seja, é uma decisão unilateral que em nenhum momento avalia as consequências trazidas para o consumidor.

Foi nesse sentido que seguiu o presente trabalho, levando em consideração que o consumidor é a parte mais afetada com a utilização da obsolescência programada, caracterizou-se quem são órgãos de defesa do consumidor em diferentes partes do mundo e como essas instituições atuam para protegê-lo contra essa estratégia de mercado, analisando assim, a prestação de um serviço público à sociedade.

Os resultados mostraram que no Brasil dos três principais órgãos de proteção ao consumidor - Procon, Decon e DPDC -, apenas o Procon apresenta posição em relação à obsolescência programada. Por parte dos órgãos públicos, não se desenvolve qualquer campanha ou projeto que tenha como finalidade eliminar essa prática das organizações. Os órgãos de defesa no Brasil atuam, principalmente, como conciliadores entre empresa e consumidor e em ações educativas e de orientação.

Nos Estados Unidos, nenhum dos órgãos pesquisados - Consumers Union, CFA e $\mathrm{NCL}$ - posicionou-se sobre a obsolescência programada, o que pode ser considerado um fato grave, levando-se em consideração que nesse país estão as sedes dos maiores fabricantes de eletrônicos do mundo. Órgãos norte-americanos agem principalmente como orientadores e conselheiros dos consumidores, embora tenham também como atribuições a investigação de casos que gerem prejuízos ao consumidor e a utilização de petições para a proteção dos consumidores; não há qualquer campanha de órgãos públicos, com visibilidade internacional, antiobsolescência sendo trabalhada no país atualmente.

Já na Europa, dois dos principais órgãos pesquisados - ANEC e BEUC - mostraram posições contrárias à obsolescência programada, sendo que a BEUC mantém uma campanha desde 2014 contra a prática dessa estratégia pelas empresas europeias. 
Quanto à legislação sobre o tema, a localidade com maior avanço é a Europa, onde há leis específicas a respeito da obsolescência programada. No Brasil, existe uma proposta do Superior Tribunal de Justiça e um Projeto de Lei, mas ambos se encontram estagnados, com aprovação e aplicação incertas. Nos Estados Unidos, não se encontrou qualquer lei ou projeto de lei acerca do assunto, apesar de que, em alguns casos específicos, o governo tem regulado o mercado e a atuação de empresas quanto à fabricação e durabilidade de produtos.

De acordo com os resultados da pesquisa pode-se concluir que entre Brasil, Estados Unidos e Europa, a última está mais avançada em relação às medidas contra a obsolescência programada, tanto na atuação dos órgãos de defesa do consumidor, quanto do ponto de vista legislativo, pela criação de leis que regulem a fabricação de produtos de forma a eliminar a utilização da obsolescência programada pelas organizações.

Verifica-se que, apesar de ter um efeito bastante negativo, não só para o consumidor, mas também para o meio ambiente, a obsolescência programada continua sendo uma estratégia bastante usada pelos fabricantes, e um tema ainda pouco discutido no âmbito jurídico e legislativo. Pode-se indicar, que o fato de as instituições que protegem os consumidores no Brasil não apresentarem campanhas que regulem a utilização da obsolescência programada na fabricação de produtos, seja devido, justamente, à falta de leis que versem sobre o tema.

Sugere-se, para outros estudos, que sejam explorados também casos concretos com decisões jurídicas sobre a obsolescência programada, para avaliar qual o entendimento da jurisprudência para essa prática, tendo em vista a escassez de leis que dissertam a respeito do assunto. Seria oportuno, também, analisar a legislação específica de outras localidades para fazer um comparativo com os resultados já encontrados; bem como, trabalhar o tema do ponto de vista ambiental, analisando os problemas trazidos ao meio ambiente pela utilização dessa prática empresarial.

Por fim, ressalta-se a necessidade de o poder público dar mais atenção às ações políticas voltadas para eliminar a má-fé na utilização da obsolescência programada como estratégia pelas empresas fabricantes de produtos e prestadoras de serviços. Deve-se entender que esse é um problema importante que vem crescendo rapidamente, principalmente no setor tecnológico, e que precisa ser tratado como prioridade pelos órgãos de proteção e pelo poder legislativo, de forma a evitar que os consumidores sejam prejudicados e enganados por empresas que usam essa estratégia como mecanismo de incentivo ao consumo as quais acabam por enfraquecer o seu poder de decisão.

\section{REFERÊNCIAS}

ALADEOJEBI, T. K. Planned obsolescence. International Journal of Scientific \& Engineering Research, v. 4, n. 3, p. 1.504-1.508, 2013.

ANEC. ANEC position on the green paper on a european strategy on plastic waste in the environment, 2013. Disponível em: http://www.anec.eu/attachments/ANEC-ENV-2013-G-008.pdf. Acesso em: 7 jul. 2019. 
ANEC. ANEC comments in support of its response to the European Commission public consultation on circular economy, 2015. Disponível em: http:/www.anec.eu/attachments/ ANEC-SUST-2015-G-024.pdf. Acesso em: 7 jul. 2019.

ANEC. About ANEC, 2018. Disponível em: https://www.anec.eu/about-anec/who-we-are. Acesso em: 7 jul. 2019.

BBB. Council of Better Business Bureaus, 2018. Disponível em: https://www.bbb.org/council/about/council-of-better-business-bureaus/. Acesso em: 25 jun. 2019.

BEUC. Towards sustainable consumption: durable goods and legal guarantees, 2014. Disponível em: http://www.beuc.eu/documents/files/FC/durablegoods/conference/presentations/Thierry_Libaert.pdf. Acesso em: 7 jul. 2019.

BEUC. Who we are, 2018. Disponível em: http://www.beuc.eu/about-beuc/who-we-are. Acesso em: 7 jul. 2019.

BRASIL. Superior Tribunal de Justiça. Recurso especial Nº 984.106-SC. Defeito manifestado após o término da garantia contratual. Relator: Min. Luis Felipe Salomão. Brasília, 4 de abril de 2012. Disponível em: http://s.conjur.com.br/dl/cdc-proteger-consumidor-obsolescencia.pdf. Acesso em: 30 ago. 2019.

CÂMARA DOS DEPUTADOS. Comissão aprova informação obrigatória sobre vida útil de bens de consumo, 2014. Disponível em: http://www2.camara.leg.br/camaranoticias/ noticias/CONSUMIDOR/479369-COMISSAO-APROVA-INFORMACAO-OBRIGATORIA-SOBRE-VIDA-UTIL-DE-BENS-DE-CONSUMO.html. Acesso em: 9 jul. 2019.

CERVO, A. L.; BERVIAN, P. A.; SILVA, R. da. Metodologia científica, 6. ed. São Paulo: Pearson Prentice Hall, 2006.

CFA. About CFA, 2018. Disponível em: http://consumerfed.org/about-cfa/. Acesso em: 5 jul. 2019.

CONSUMER CHAMPION. BEUC launches durable goods campaign, 2014. Disponível em: http://www.consumerchampion.eu/news/beuc-launches-durable-goods-campaign. Acesso em: 7 jul. 2019.

CONSUMERS UNION. About us, 2018. Disponível em: http://consumersunion.org/ about/. Acesso em: 5 jul. 2019.

ECU. About us, 2018. Disponível em: http://europeanconsumersunion.eu/about=-us/?langen. Acesso em: 7 jul. 2019. 
EPRS. Planned obsolescence: exploring the issue, 2016. Disponível em: http://www.europarl.europa.eu/RegData/etudes/BRIE/2016/581999/EPRS_BRI\%282016\%29581999_ EN.pdf. Acesso em: 4 ago. 2019.

EUROBAROMETER. Attitudes of europeans towards building the single market for green products, 2013. Disponível em: http://ec.europa.eu/commfrontoffice/publicopinion/flash/ fl_367_sum_en.pdf. Acesso em: 4 ago. 2019.

EUROPEAN COMMISSION. The ECC-Net promotes the understanding of EU consumers' rights and assists in resolving complaints about purchases made in another country of the network, when travelling or shopping online, 2018. Disponível em: $<$ http://ec.europa.eu/consumers/solving_consumer_disputes/non-judicial_redress/ecc-net/index_en.htm. Acesso em: 28 jun. 2019.

FACHIN, O. Fundamentos de Metodologia, 5. ed. São Paulo: Saraiva, 2006.

GIL, A. C. Métodos e técnicas de pesquisa social, 6. ed. São Paulo: Atlas, 2008.

. Como elaborar projetos de pesquisa, 4. ed. São Paulo: Atlas, 2002.

GUGLINSKI, V. Breve histórico do Direito do Consumidor e origens do CDC, 2013. Disponível em: https://vitorgug.jusbrasil.com.br/artigos/112106596/breve-historico-do-direito-do-consumidor-e-origens-do-cdc. Acesso em: 4 ago. 2019.

HG.ORG. Planned obsolescence - should be an offense punishable like any deception, 2018. Disponível em: https://www.hg.org/article.asp?id=33946. Acesso em: 5 jul. 2019.

IDEC. Mais da metade dos equipamentos eletrônicos é substituída devido à obsolescência programada, 2014. Disponível em: http:/www.idec.org.br/o-idec/sala-de-imprensa/release/mais-da-metade-dos-equipamentos-eletronicos-e-substituida-devido-a-obsolescencia-programada. Acesso em: 3 jul. 2019.

KEEBLE, D. The culture of planned obsolescence in technology companies, 2013, 50s. Bachelor's thesis (Business Information Technology), Oulu University of Applied Sciences, Oulu, Finland.

KHALEELI, H. End of the line for stuff that's built to die? 2015. Disponível em: https:// www.theguardian.com/technology/shortcuts/2015/mar/03/has-planned-obsolesence-had-its-day-design. Acesso em: 9 jul. 2019.

LONDON, B. Ending the depression through planned obsolescence [Working Paper]. University of Wisconsin, Madison, WI, 1932. 
MAYCROFT, N. Consumption, planned obsolescence and waste [Working Paper]. University of Lincoln, Lincoln, UK, 2009.

NCL. About NCL, 2018. Disponível em: http://www.nclnet.org/about_ncl. Acesso em: 5 jul. 2019.

PACKARD, V. The waste makers. New York: David McKay Company, 1960.

PORTAL DO BRASIL. Acesse lista com as entidades de proteção ao consumidor, 2009. Disponível em: http://www.brasil.gov.br/cidadania-e-justica/2009/10/acesse-lista-com-as-entidades-de-protecao-ao-consumidor. Acesso em: 10 mai. 2019.

PROCONRJ. Consumo sustentável VII: a obsolescência programada, 2012. Disponível em: http://www.procon.rj.gov.br/index.php/publicacao/detalhar/222. Acesso em: 3 jul. 2019.

REIBOLDT, W.; MALLERS, M. H. Consumer survival: an encyclopedia of consumer rights, safety and protection. Santa Barbara: ABC-CLIO, 2014.

RODAS, S. CDC deve proteger consumidor da obsolescência programada, diz ministro, 2015. Disponível em: http://www.conjur.com.br/2015-jun-25/cdc-combater-obsolescencia-programada-ministro-salomao. Acesso em: 9 jul. 2019.

SILVA, M. B. O. (2012). "Prêt à jeter": obsolescência programada e teoria do decrescimento frente ao desenvolvimento e ao consumo. In: XXI encontro nacional do conpedi Uberlândia, 2012, Uberlândia. Anais... Uberlândia: Fundação José Arthur Boiteux, 2012, p. 5.435-5.451.

SPINKS, R. We're all losers to a gadget industry built on planned obsolescence, 2015. Disponível em: https://www.theguardian.com/sustainable-business/2015/mar/23/were-are-all-losers-to-gadget-industry-built-on-planned-obsolescence. Acesso em: 5 mai. 2019.

SUEZ. Electronic devices: planned obsolescence outlawed, 2015. Disponível em: http:// www.emag.suez-environnement.com/en/electronic-devices-planned-obsolescence-outlawed-14146. Acesso em: 9 jul. 2019.

THE ECONOMIST. Planned obsolescence, 2009. Disponível em: < http:/www.economist. com/node/13354332>. Acesso em: 5 mai. 2019.

TRABALÓN, P. B. Obsolescencia programada: realidad o ficción, 2012. Disponível em: https://academiabasuracero.files. wordpress.com/2016/06/boquer-paula-obsolescencia-programada.pdf. Acesso em: 5 mai. 2019. 
YOUR EUROPE. Guarantees and returns, 2018. Disponível em: http://europa.eu/youreurope/citizens/consumers/shopping/guarantees-returns/index_en.htm. Acesso em: 9 jul. 2019.

\section{DADOS DOS AUTORES}

\section{Antonio Edson Oliveira Honorato}

Mestre em Ciências Sociais e Humanas pela Universidade do Estado do Rio Grande do Norte (UERN), especialista em Gestão Estratégica de Serviços e graduado em Administração pela Universidade Federal Rural do Semi-Árido (UFERSA). Professor substituto da UFERSA.

\section{Eddla Karina Gomes Pereira}

Doutora em Desenvolvimento e Meio Ambiente (UFPB), mestra em Ciências Jurídicas (UFPB), possui máster em Gênero e Políticas de Igualdade (Universidad de Valencia/Espanha). É especialista em Direito Processual (UNISUL) e graduada em Direito (UNIPÊ). Professora Adjunta da Universidade Federal da Paraíba (UFPB).

Submetido em: 19-9-2019

Aceito em: 14-10-2020 